EXPERIENCE IN DESIGNING AND OPERATING COMPUTER CONTROLLED REACTOR FACILITIES

\title{
(1) MASTER
}

Garth E. Driver

Battelle Memorial Institute Pacific Northwest Laboratory

July 12, 1968

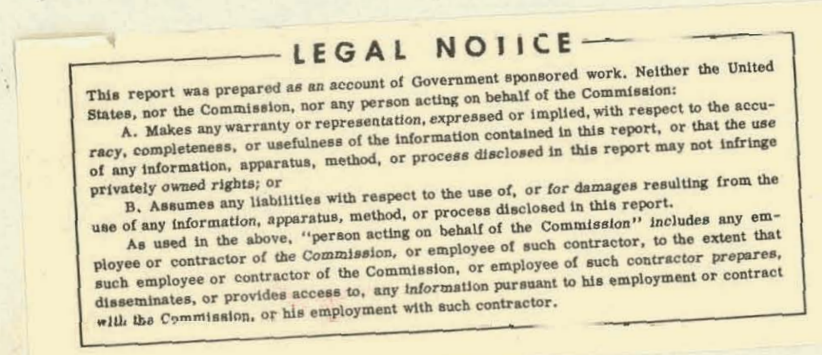
(a) This paper is based on work performed under United States Atomic Energy Commission
Contract AT $(45-1)-1830$. 


\section{DISCLAIMER}

This report was prepared as an account of work sponsored by an agency of the United States Government. Neither the United States Government nor any agency Thereof, nor any of their employees, makes any warranty, express or implied, or assumes any legal liability or responsibility for the accuracy, completeness, or usefulness of any information, apparatus, product, or process disclosed, or represents that its use would not infringe privately owned rights. Reference herein to any specific commercial product, process, or service by trade name, trademark, manufacturer, or otherwise does not necessarily constitute or imply its endorsement, recommendation, or favoring by the United States Government or any agency thereof. The views and opinions of authors expressed herein do not necessarily state or reflect those of the United States Government or any agency thereof. 


\section{DISCLAIMER}

Portions of this document may be illegible in electronic image products. Images are produced from the best available original document. 
EXPERIENCE IN DESIGNING AND OPERATING

COMPUTER CONTROLLED REACTOR FACILITIES

Garth E. Driver

\section{Introduction}

It is to be expected that a new, fast-growing technology bring along with it a new set of problems; but some of those which have attended the development of digital computer control are of a kind not previously encountered by the control engineer. First, the equipment is basically different. To be of any value at all, it must be provided with an intangible called software. Second, the computer manufacturer has been continually and rapidly improving the power and reliability of his machines. However, his eye has often been on the huge data processing market rather than the relatively small process control field which has been only an incidental beneficiary of most of the basic development. Third, the process engineer himself has caused some of the trouble. His enthusiasm for progress has led to controversy over such things as "breakeven points", whereby the cost of a number of analog recorders and controllers was compared against that of a digital system which would do nothing more than simulate the analog devices. The wide range of results of such comparisons shoved, at one extreme, that the full capability of the digital computer had not been counted, and at the other, that the cost of computer programming had been all but disregarded. 
In spite of a somewhat fitful adolescence, the field is beginning to show signs of maturity. Operating experience has provided a basis for judging the worth of different kinds of control system, and some manufacturers are using such experience to develop better control equipment. The computer programs are being given more attention. And there is a growing. trend away from thinking of computers as three-mode controllers, and toward justifying them on the basis of their ability to do things that are difficult or impossible with conventional analog equipment.

During the past three years the Pacific Northwest Laboratory has installed nine process computers in applications ranging from on-line data. acquisition and analysis to extensive plant controi: The installations include nuclear chemical processes, mass spectrometers, hybrid computers, and experimental and test reactors. This paper discusses the problems associated with developing, procuring, installing, and checking out computer-based data handling and control systems. The scope is confined to those aspects which exist because of the presence of a digital computer. Project Planning

Whether the installation is to be large or small, it is important that those responsible for the management and operation of the facility be informed of the unusual aspects of dealing with a computer-based system. Everyone concerned with the project should be made to understand this basic fact: a large and essential part of the system design is in the computer program. The software takes the place of controllers, summers, multipliers, and square root extractors of an analog system. It also replaces the interconnecting wiring among sensor terminals, output signal leads, operator's console, and displays. A good grasp of this situation helps greatly to reconcile project and plant personnel with the unconventional cost structure, schedule, and lines of authority which they will encounter. 
Consider the system cost. There are the usual expenditures for planning, developing, specifying, buying, and installing the equipment. These can be adequately estimated using standard rules and manufacturers' catalogs. But there is also computer programming. Equalling roughly 30 to 100 percent of computer system hardware cost, programming accounts for a substantial portion of the project expense. Furthermore it is usually difficult to estimate because a sufficient background in prior work is lacking, or has been of a developmental nature where accurate recurds of actual programming costs were not kept. Under these circumstances, a firm idea of the relationship of programs to system design is needed to avoid large errors in forecast cost; and while the point may appear trivial to an experienced computer control engineer, its importance is suggested by the scarcity of projects in which programming expense has been over-estimated.

Project schedules are also different when a digital computer is involved. A large part of program debugging and modifying must be done after the computer and essential peripherals are delivered and installed. For a large system this step might require more than a year's time. Furthermore, the period between ordering and delivery of the hardware can exceed 18 months. Add to this the time needed to install and check out the equipment, and one finds that more than three years can elapse between award of the computer purchase order and reactor startup. Again, the fundamental cause of the extended schedule for computer-based control and data handling is the amount of basic design resident in the computer programs; and again, that fact must be made clear to project management in order to assure smooth coordination with overall plant design and construction. 
A third area which has been affected by computers is that of project lines of authority. There is a new position in the organization occupied by the engineer in charge of computer programs (and as much of the hardware as his time and capability allow). He knows the functions of all of the routines in the software, how they fit together into working programs, and how they serve the data and control needs of the plant. In addition to the aforementioned equivalence of software and system design, a second basic fact makes his position important: a large part of the plant operating procedure is imbedded in the computer programs. This is true whether the control system is highly automatic, or open loop with operator guidance. With the above in mind, one can readily see that the computer program defines the behavior of the control system and the plant. The programming supervisor is thus thrust into a place of emminence. He must determine all of the functions required of the control system, translate these into a program specification, and see to it that said specification becomes established as an official, fully approved project document fò̃ guiding his staff of programmers.' He must be consulted on every plant design change which could require program modification, and be given sole approval authority for such program modification. This last is necessary because the other plant designers usual.1y have no. idea of the kind of havoc which can be inflicted upon the programming statt by a tew "minor" design changes. Finally, the programming leader must work closely with the operating staff, interpreting plant procedures into the softvare specification, giving advice on the impact of any proposed changes, and providing for the training of future plant operators and control system programmers. The need to set up these formal lines of conmunication, strict administrative procedures, and firm programming guidelines cannot be overstated. The failure to do so in the past has been a common cause of broken schedules and enormous programming cost. 
System Engineering

Nearly. every phase of control engineering from initial development to final checkout takes on a different color when there is a computer in the system; the main reasons are the time-sharing nature of the equipment and the computer software.

One of the beginning steps in developing the equipment configuration is to make a preliminary list of all sensor inputs to the system, control point outputs, and displayed variables. Instead of relating these to a number of independent information channels, one must consider them in terms of the interfaces between computer and process, and computer and plant operators. This requires studying the process time constants to determine input and output sampling rates, and assessing input signal characteristics to find the amount of signal conditioning hardware which will be needed. In a system which acquires data from a large number of sensors, sampling rate and signal preconditioning influence heavily the system size and cost. Even at this early stage the services of an expert programmer are sought to evaluate, for example, the extent to which digital filtering by software can reduce the multiple analog filters in the input interface. At the next step he is even more heavily relied upon to translate the input-output list and system functions into a tentative program structure for an estimate of basic computer speed and memory capacity.

It is customary during these early design activities to decide between a punched card and a paper tape oriented system usually in favor of the former. Punched paper tape got a head start in the era when the cost of digital control equipment was forced as low as possible in order to compete with conventional analog hardware, and tape has been predominant up to the present partly out of 
habit. Manufacturers bid against each other with low equipment cost in mind, and control engineers have become accustomed to and tolerant of the disadvantages of paper tape. - We have learned, however, that a true comparison must take into account several factors other than price. One is that it takes a rather elaborate paper tape editor program just, to take the place of punching and shuffling cards by hand. Another is that tape editing ties up a computer, usually the pròcess computer itself because it is the only machine of its kind readily available. A third is that, at least within the current technology, punched cards are a somewhat faster medium of data handling. For these reasons the use of a punched card oriented system should be seriously considered, especially in applications where the computer programs are frequently modified.

Also during preliminary system design there arises the question of memory storage options. These range from all magnetic core to minimum core with auxiliary drum or disc, both of which are suitable for special applications. However, process computer memories will generally fall between these extremes. The intermediate speed storage is very attractive for storing large amounts of data, systems software such as assemblers and compilers, and some of the working application programs; but neither drum, disc, nor tape is an equivalent substitute for core storage: The pitfall here is that the designer, feeling secure with a large bulk store, mighl allempl lo economize by using the smallest core offered by the manufacturer. The'resulting complex executive program needed to shuttle his working routines into and out of an inadequate core memory could cost much more than any anticipated savings in hardware investment.

After the preliminary design is completed, the job of writing the system specification forces the issue of who is to do the programming (if the subject was not settled at an earlier stage). There is, of course, no answer to the question to fit all occasions; however, a few general guidelines will apply in 
most cases. As a rule, there will be three different groups involved with the computer programs: the plant operating staff, the plant instrument and control engineers, and the computer manufacturer. At the very least, the operators will have to feed program tapes or cards into the computer, the control engineers must know the functions of the applications programs, and the manufacturer will have developed the utility software such as assemblers, compilers, and loaders. Beyond these is the main task of developing the data acquisition and control programs. At this point the user is tempted to write a set of strictly functional specifications and lay the entire burden of hardware and programs on the equipment: supplier;after all, what he wants is a good; reliable data and control system regardless of how it is put together. There are, however, three serious disadvantages to this seemingly attractive approach: (1) the choice of hardware is limited to that made by a company which happens to have the programming talent available at the particular time; (2) the field is further narrowed to the very few manufacturers, if any, who have had experience with a similar nuclear facility; and (3) the user is very likely to end up with none of his own personnel really knowing how the computer works, and thus unable to improve or enlarge the system as required by future plant modifications. Some of these objections can be overcome by hiring a systems engineering firm to do the entire job, but a continuing in-house programming capability would still be lacking. At the other extreme, the user might elect to do all of the process programing. This approách has been satisfactory in the past as long as the control engineers include enough plant operators on the programming staff to ensure that future small software changes can be made without the continual help of the instrument and control development personnel. Once in a while a project 
will come along which is too large for the user's programmers to handle without an unreasonable increase in staff. In this event, programming assistance can be purchased from the manufacturer. But the responsibility for developing the software structure, integrating the sub-programs, and debugging the system should remain with project personnel; and these must still be prepared to write all of the programs if unforseen circumstances so.require. Of course, the above remarks hold true only in an establishment such as the author's laboratory where a continuing workload in process control justifies maintaining a sizeable control engineering group. If company size or policy does not permit building a substantial process programming capability, the user must rely more heavily on the system supplier; the software development becomes more of a joint venture. The important point is that plant personnel must become involved to the extent that both control engineers and process operators can carry on future software development after the system manufacturer leaves the scene.

The specification will also have to cover system software. In contrast to the process programs just discussed, the systems package comprises those programs which help in the writing of control programs, and such other non-process functions as internal fault diagnosis. With the exception of the diagnostics, the systems programs are not run during plant operation. Aided by a strange vocabulary and great faith in his. product, the computer salesman can make it very hard to understand the real capability of his software; it is therefore strongly advised that a highly experienced programmer be retained to write or reviev this part of the specification.

The same kind of expert will be needed when the time comes to evaluate proposals and make the system selection, especially if the equipment is to be acquired through competitive bidding. The most difficult task at this stage of the project is to assess the relative capabilities of the computers. These may be offered in 
a number of combinations of word length, memory size, arithmetic speed, and instruction repertoire, all of which influence the true power of the machine. And these factors combine in a complex way. For example, an 8,000-word core memory of 12-bit words is not equivalent to a 4,000-word core of 24-bit words; which one is superior depends on the manner of word manipulation and the instructions available. These last remarks are intended mainly to emphasize the need to evaluate candidate computers from both a programming and a hardware viewpoint. It has been found helpful to devise small trial programs and code them into the language of the proposed system in order to compare memory storage used and program running times. This procedure also gives some idea of the relative difficulty of programming the competing systems.

A computer-based system also requires different delivery and installation procedures from those which suit analog equipment. In a new plant, the time needed for program development and debuy often dictates equipment delivery prior to completion of the control room construction; therefore a temporary facility must be planned. Even then the control system engineers will strive to move the system into the control room as early as is feasible in order to take full advantage of its ability to speed up the checkout of input-output signal paths, and to begin determining system noise sources. This 'seemingly premature installation has shown to be well worthwhile, in spite of such inconveniences as temporary electrical power hookups, construction noise, and inadequate heating or ventilation.

\section{Experience with the HTLTR}

The High Temperature Lattice Test Reactor and its supporting facility is used to determine basic reactor physics parameters and to test reactor core designs at 
high temperatures. It is a ten-foot cube of graphite blocks surrounded by thermal insulation and an outer steel shell. A $5 \times 5 \times 10$ foot center section is removable for replacement with a test core. Although the maximum nuclear power is only 2 killowatts, the reactor is designed to be heated to $1000^{\circ} \mathrm{C}$ using 384 kilowatts of electrical power. Heat is generated by 24 graphite bars carrying electrical current at a nominal $28 \mathrm{v}$ a.c. The reactor is supplied with a nitrogen atmosphere to inhibit graphite oxidation and to provide rapid cooling after a hightemperature run. The nuclear control comprises eight horizontal control rods, four vertical safety rods, and one shim rod.

A digital computer controls the acquisition of sensor data and generates direct actuator control signals for essentially all reactor systems, including parts of the nuclear system and the safety circuit. The operational programs contain over 20,000 instructions and provide automatic feedback control of the gas and heating systems through their eight different modes of operation. The nuclear control system differs in that a) power to the control rod drives is controlled by a switch operated by the operator and b) an auxiliary flux monitoring system, not tied to the computer, is provided. All control point data (nuclear power, flows, pressures, temperatures, reactivity, electrical power, etc.) and alarms are displayed for the operator on a three-color cathode-ray tube in alphabetic and numerical form. 'l'he control computer is a Digital Equipment Corporation PDP-7 with 8000-word core memory and three small magnetic tape units. The system includes a 128-channel relay multiplexer for analog signals, two 17-bit parallel binary inputs for flux signals, output multiplexer, and operating peripherals. Functional design tests of the reactor systems, using the operational programs, began in May 1967 and were completed in November. The first four months of full operation with metal fuel limited temperatures to $400^{\circ} \mathrm{C}$. A high temperature uranium-thorilimi test core was loaded in May 1968. 
During the planning of the HTLTR the data and control system assumed three different forms. At first only conventional analog equipment was considered. It soon became apparent, however, that the nature of the facility dictated more advanced data acquisition; so á computer data logging system was included. Finally, the designers settled on the present configuration in which nearly all data acquisition and process actuators are directly computer controlled... As a result of this decision it was soon discovered that experience in engineering this kind of system was very limited even among the combined talents of the project administration, the architect-engineer, and the potential hardware supplier. The situation made necessary an unusually intimate liaison among the contributing parties, a practice which is still found advisable whenever computers are involved in a system.

The early stages of conceptual design were concerned mostly with equipment. Programming was at first set dside in the urgency of developing a hardware configuration and its specification. Later, a small study of control algorithms was conducted and trial programs were run on a GE 412 computer to get some idea of the software which would be needed. An informal estimate at that time placed the required programming effort at something less than one man-year. Work was begun on several HTLTR applications programs during the interval between equipment purchase and delivery, among them the heater control and CRT display routines. Upon delivery of the hardware, some of the programming activity was diverted to straightening out the manufacturer's utility software to fit the specific H'ILTR configuration.

At this point the project was about half way to completion and the progress in programming was disappointing. Isolated function programs were being written and then rewritten, sometimes on the basis of casual conversations between programmers and plant operators. A thorough stuly of the situation produced the recommendations previously discussed.' A programming manager was appointed and 
established as the sole authority for setting or changing program requirements. A detailed software specification was drawn up and confirmed by project management as the official guiding document. And a schedule was published which clearly defined all of the tasks to be done; showed the relationships among executive, monitor, and function programs; and forced their being developed in the proper order. Thus began the truly productive program development which, thanks to a dedicated and hard-working staff, was completed on schedule and in time for initial reactor tests, at which point the software effort had amounted to about six man-years. Of course, the programming work did not end at reactor start-up. In an experimental facility such as the HTLTR it is expected to continue: However, several of the facility staff were instructed in the software system and participated in developing the applications programs; so the job of carrying on with software development is now being done entirely by operating personnel, which is proper in view of their knowing best the needs of the facility. $1::$

of all the outward changes brought about by the digital computer, the most striking is the control room operating procedure. The computer-directed inputoutput devices have permitted concentrating operator communication within a very small area. High-speed process display is by a three-color cathode-ray tube (CRT) which shows reactor power level and period, rod positions, excess reactivity, and off-normal alarms. Other process data such as gas flow, can be displayed at the operator's request. The added ability to present a digital readout of any process input signal has proved very useful in system majntenance and checkout. Messages of lower priority are transmitted to the operator by a teletype printer, and data logs are output by a second typewriter which is outside the operator's immediate scope. All operator communication to the system is through a rod movement switch, an emergency shutdown pushbutton, and the teletypewriter keyboard. 
The control room staff has accepted the system with enthusiasm despite the burden of many tedious hours of program debugging. Nearly half of the operators have learned to program the computer with skill, even though the position does not require it. They soon commit to memory the more frequently used of the 160 typed commands to the system, and an initial lack of typing ability appears to be small hindrance.

Maintenance experience has followed the anticipated pattern. Failure of the computer itself has caused no reactor shutdowns, but the peripherals have given trouble. Frequent teletype repair has been reduced by replacing the original models with more rugged and expensive machines. The color CRT, being the first of its design, required circuit modifications before attaining its present state of reliability. And the mercury-wetted multiplexer switches are showing signs of wear. Nevertheless, the overall system reliability is more than adequate for the HTLTR application.

Operation with the computer system has revealed several design shortcomings which are being corrected as time permits. A self auditing routine has been added to the programs to detect the occurrence of an endless loop and to help in locating the cause. The CRT display format has been rearranged and augmented with additional data. New logging routines are being added to make data analysis more efficient. The third magnetic tape unit was added to provide more data storage and a back-up source of essential applications programs.

A shutdown log routine is being written which will check out all systems for proper down condition, type an "ok" message if all is in order, then erase the entire core memory to ensure no further control action. Another program under development will allow unattended off-hours operation during the long heat- 
up and cool-down periods by sending an alarm to a teletype printer in a nearby facility where there are operators around the clock. Besides indicating offnormal conditions, the system will also send messages which explain the corrective action to be taken. The capability for this kind of growth and refinement through software development is typical of the benefits of a computer control system. 